$\mathrm{H}$

$\mathrm{H}$

\title{
Effective andragogical strategies: What works with teachers? Reflection on practice
}

Anita Seguna ${ }^{*}$

Esmeralda Zerafa ${ }^{b}$

Suggested Citation:
$M v \quad q m \quad m$
$q b \quad m f f t$
$m$
$m \quad b \quad b \quad m b$ :

Abstract 
$\begin{array}{llllllllllll}m & q & b & m f f t & m & m & m & b & b & m b & :\end{array}$

1. Introduction

$\mathrm{H}$

2. Literature Review

2.1. Constructive Alignment, Multiple Intelligences (Gardner, 1983) and Bloom's Taxonomy (Bloom, 1956)

$\mathrm{H}$

$\mathrm{H}$

$\mathrm{H}$ 
2.2. Creating a Reflective Professional Learning Community

$\begin{array}{llll}\mathrm{H} & Q & b & B \times b\end{array}$

3. Research Design 


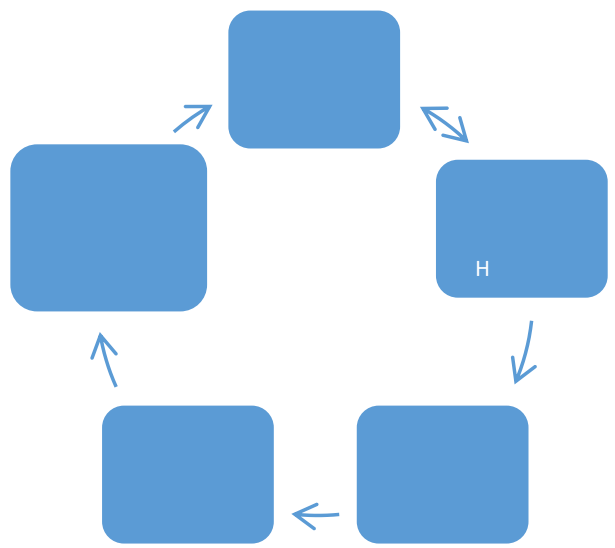

Figure 1. Training Needs Analysis Cycle

(Furze \& Pearcey, 1999)

Figure 2. Training Needs Analysis

Cycle (as adapted for the study)

3.1. Sessions' content

$\mathrm{H}$

3.2. Strategies employed during session delivery

$\mathrm{H}$

$\mathrm{H}$ 
$\begin{array}{llllllllll}m & q b & m f f t & m & m & m & b & b & m b\end{array}$

\section{Data Analysis}

Table 1. Average Scores from ACT and LALs

$\mathrm{H}$

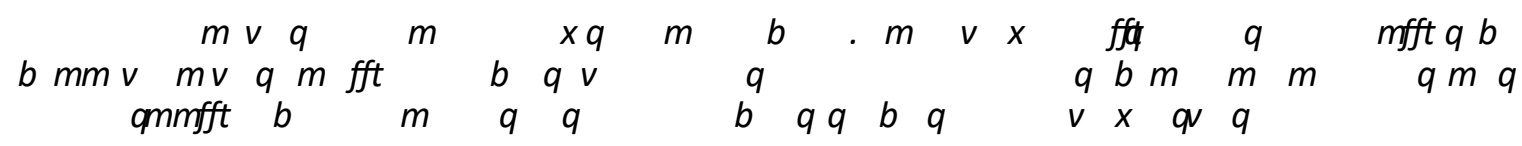


Table 2. Average Scores from Teaching Staff and LSAs 
$\begin{array}{llllllllll}m & q b & m f f t & m & m & m & b & b & m b\end{array}$

\section{References}

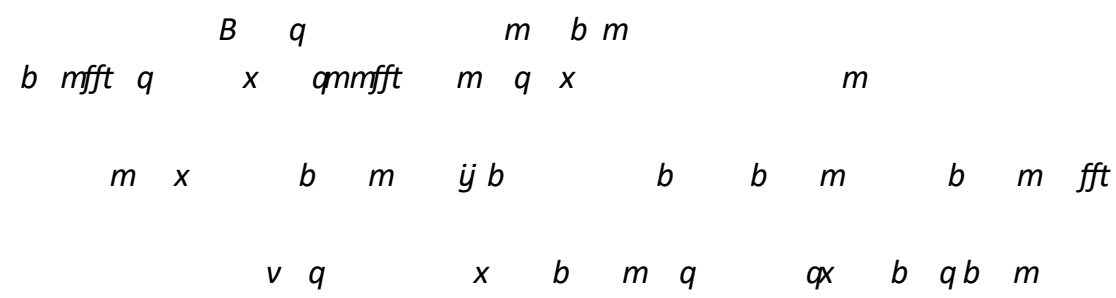

$q q \times 24$

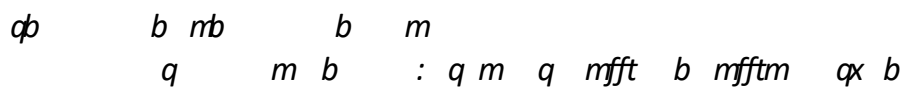

M $q$ mfft1

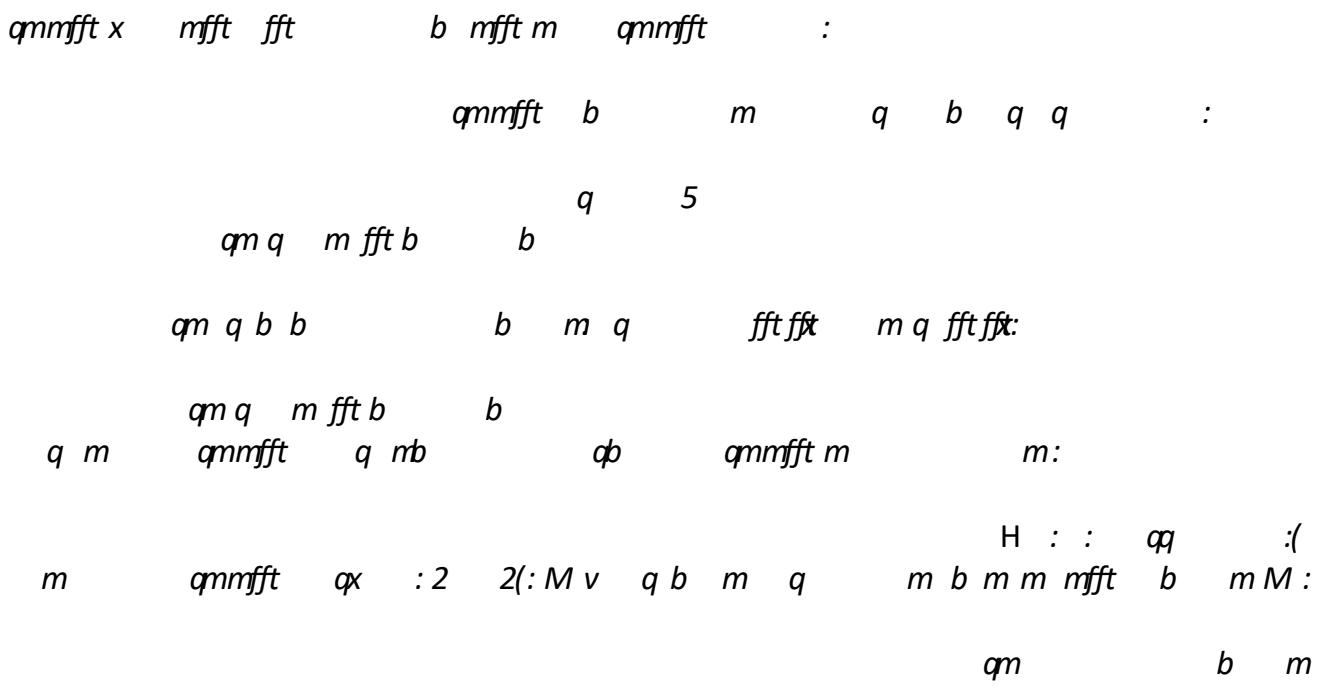

31

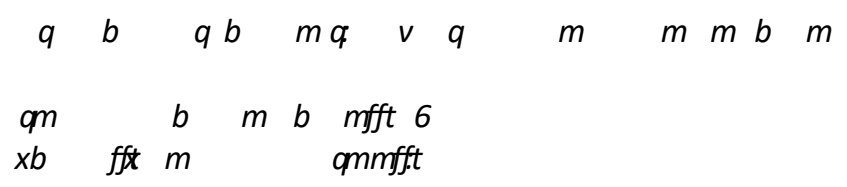

